\title{
Ergenler İçin Zihinsel Dayanıklılık Ölçeği: Türkçe Uzun ve Kısa Formun Psikometrik Özellikleri
}

\author{
Yağmur Soylu $^{* 1}$, Ali Serdar Sağkal ${ }^{2}$ ve Yalçın Özdemir ${ }^{3}$
}

Öz

Bu çalışmada, Ergenler Iç̧in Zihinsel Dayanıklılık Ölçeğinin (EIZZDÖ) Türkçe uzun ve kısa formunun psikometrik özellikleri incelenmiştir. Araştırmada, 11-18 yaş ortaokul ve lise öğrencilerinin yer aldığ $\mathrm{iki}_{\mathrm{i}}$ ayrı örneklem grubundan $\left(N_{1}=357, \% 54.6\right.$ erkek, $O r t_{\text {yaș }}=14.92, s s_{\text {yaș }}=2.09 ; N_{2}=307, \% 52.4$ erkek $O r t_{\text {yas }}=14.97, s s_{\text {yas }}=1.55$ ) veri toplanmıştır. Doğrulayıcı faktör analizi sonuçları, EIZZDÖ'nin 18 maddeli altı faktörlü orijinal yapısı ile 6 maddeli tek faktörlü kısa formunun hedef örneklemde doğrulandığını göstermiştir. Araştırmada, EİZDÖ uzun ve kısa formu ile Çocuk ve Genç Psikolojik Sağlamlık Ölçeği (ÇGPSÖ-12) toplam puanları arasında anlamlı korelasyonlar saptanmıştır. EİZDÖ'nin uzun ve kısa formuna ait Cronbach alfa katsayıları sırasıyla .85 ve .72 olarak hesaplanmıştır. Çapraz geçerlik ve güvenirlik bulguları, EİZDÖ’nin kısa formunun psikometrik özelliklerini desteklemiştir. Çoklu grup doğrulayıcı faktör analizi sonuçlarına göre, EİZDÖ’nin kısa formunun ergenliğin gelişim aşamalarına ve cinsiyete göre yapısal ve metrik açıdan değişmez olduğu belirlenmiştir. Araştırma sonuçları, EİZDÖ'nin uzun ve kısa formunun gelecek çalışmalarda eğitim ortamlarında 11-18 yaş ergenlerin zihinsel dayanıklılık düzeylerinin değerlendirilmesinde geçerli ve güvenilir bir ölçme aracı olarak

\author{
Anahtar Sözcükler \\ Ergenler \\ Zihinsel dayanıklılık \\ Geçerlik \\ Güvenirlik \\ Makale Hakkında \\ Gönderim Tarihi \\ 04 Nisan 2019 \\ Kabul Tarihi \\ 24 Temmuz 2019 \\ Makale Türü \\ Araştırma Makalesi
}

\section{Mental Toughness Scale for Adolescents: Psychometric Properties of Turkish Long and Short Form}

\section{Abstract}

In this study, psychometric properties of Turkish long and short version of the Mental Toughness Scale for Adolescents (MTS-A) were examined. In the research, data were collected from two different samples that consisted of 11 to 18 -year-old middle and high school students $\left(N_{1}=357,54.6 \%\right.$ boys, $M_{\text {age }}=14.92$, $s d_{\text {age }}=2.09 ; N_{2}=307,52.4 \%$ boys, $\left.M_{\text {age }}=14.97, s d_{\text {age }}=1.55\right)$. The results of confirmatory factor analysis indicated that both 18 -items six-factor original structure and 6-item one-factor short form structure of the MTS-A were confirmed in the present data. In the research, we detected significant correlations between long and short form of the MTS-A and Child and Youth Resilience Measure (CYRM-12). Cronbach's alpha coefficients for MTS-A long and short form were .85 and .72 , respectively. Results of the cross-validation and reliability study supported the psychometric properties of short form of the MTS-A. The results of multiple-group confirmatory factor analysis supported that short form of the MTS-A has configural and metric invariance across stages of adolescent development and gender. Research results highlighted that both the original and short form of the MTS-A is a valid and reliable instrument to assess 11 - to 18-year-old adolescents' mental toughness levels. Research findings were discussed, limitations and suggestions were proposed.
Keywords

Adolescents Mental toughness

Validity

Reliability

Article Info

Received

April 04, 2019

Accepted

July 24, 2019

ArticleType

ResearchPaper

Attf: Soylu, Y., Sağkal, A. S. ve Özdemir, Y. (2019). Ergenler İçin Zihinsel Dayanıklılık Ölçeği: Türkçe uzun ve kısa formun psikometrik özellikleri. Ege Eğitim Dergisi, 20(1), 322-334. doi:10.12984/egeefd.549515

\footnotetext{
${ }^{*}$ Sorumlu Yazar/Corresponding Author

1 D Dokuz Eylül Üniversitesi, Buca Eğitim Fakültesi, Eğitim Bilimleri Bölümü, Rehberlik ve Psikolojik Danışmanlık Anabilim Dalı, Türkiye, yagmur.soylu@ deu.edu.tr

2 다 Aydın Adnan Menderes Üniversitesi, Eğitim Fakültesi, Eğitim Bilimleri Bölümü, Rehberlik ve Psikolojik Danışmanlık Anabilim Dalı, Türkiye, aliserdarsagkal@gmail.com

3 달 Aydın Adnan Menderes Üniversitesi, Eğitim Fakültesi, Eğitim Bilimleri Bölümü, Rehberlik ve Psikolojik Danışmanlık Anabilim Dalı, Türkiye, yalcin.ozdemir@adu.edu.tr
} 


\section{Extended Abstract}

\section{Introduction}

Mental toughness is proposed as a crucial coping mechanism to deal with daily stressors and pursuit of goaldirected behaviors (St Clair-Thompson, 2017). Theoretical perspectives highlight that mental toughness is closely related to positive psychology attributes and mental skills (Connaughton, Hanton, Jones, \& Wadey, 2008). It is argued that as a state-like trait, mental toughness is shaped by environmental factors and helps individuals to deal with daily stressors and challenging and adverse events (Gucciardi, Hanton, Gordon, Mallett, $\&$ Temby, 2015). Therefore, in recent decades, researchers paid special attention to conceptualizing attributes of mental toughness, uncovering factors and mechanisms that underlie mental toughness as well as outcomes of mental toughness (Sorensen, Schofield, \& Jarden, 2016). Particularly, McGeown, St Clair-Thompson, and Putwain (2018) conceptualized six main attributes of mental toughness, namely, commitment, challenge, control life, control emotions, confidence in abilities, and interpersonal confidence. Commitment refers to abilities to deal with problems successfully despite obstacles. Challenge refers to attempts for self-development. Control life refers to perceptions and feelings regarding one's control on his or her life. Control emotions refers to the skills of regulation of emotions in difficult situations. Confidence in abilities refers to the perceptions regarding one's confidence in his or her abilities to deal with difficult tasks. Lastly, interpersonal confidence refers to the feelings of confidence in unfamiliar social environments. Indeed, consistent with theoretical expectations, empirical findings indicate that attributes of mental toughness are associated with improved academic achievement, attainment, classroom behaviors, and peer relationships (St Clair-Thompson et al., 2015). It is also demonstrated that mental toughness importantly contributes to successful educational transitions (Crust et al., 2014; St ClairThompson et al., 2017). Nevertheless, the number of research examining the role of mental toughness in educational settings is relatively limited in comparison to sports or mental health fields (McGeown, St ClairThompson, \& Clough, 2016). To the best of our knowledge, no study has yet investigated the role of mental toughness in Turkish school contexts. Considering the protective role of mental toughness on individual and school-related outcomes, developing and/or adapting instruments for assessing attributes of mental toughness of middle and high school students would fill an important gap in Turkish literature. To this end, the present study aims to adapt Mental Toughness Scale for Adolescents (MTS-A; McGeown et al., 2018) into Turkish and investigate its psychometric properties on 11-to 18-year-old adolescents.

\section{Method}

In the research, data were collected from two separate samples that consisted of 11-to 18-year-old middle and high school students $\left(N_{1}=357,54.6 \%\right.$ boys, $M_{\text {age }}=14.92, s d_{\text {age }}=2.09 ; N_{2}=307,52.4 \%$ boys, $M_{\text {age }}=14.97$, $s d_{\text {age }}=1.55$ ). While we performed validity (construct validity, criterion-related validity) and reliability (Cronbach's alpha coefficients) analyses on the data from the first sample, we used data from the second sample for analyzing cross-validation (construct validity) and reliability (Cronbach's alpha coefficient and test-retest reliability) of Turkish short form version of the MTS-A. In the research, we used MTS-A and Child and Youth Resilience Measure (CYRM-12) as measuring instruments. The MTS-A was developed to assess mental toughness levels of 11-to 18-year-old adolescents (McGeown et al., 2018). The MTS-A consists of 18 items and six subscales (commitment, challenge, control life, control emotions, confidence in abilities, and interpersonal competence; three items in each). Items are rated on a 4-point Likert scale $(1=$ strongly disagree, $4=$ strongly agree), with higher scores indicating greater mental toughness. In the original study, six-factor structure provided a good fit to the data and Cronbach's alpha coefficients ranged from .73 to .79. The MTS-A scores were associated with greater academic motivation and engagement; and lower anxiety and depression (McGeown et al., 2018). CYRM-12 is, on the other hand, a self-report instrument to assess resilience of children and adolescents (Arslan, 2015; Liebenberg, Ungar, \& LeBlanc, 2013). CYRM-12 consists of 12 items and onefactor structure. Items are rated on a 5-point Likert scale $(1=$ not at all, $5=a$ lot $)$, with higher scores reflecting greater levels of resilience. In the present study, Cronbach's alpha coefficient for CYRM-12 was .84. SPSS 25.0 and AMOS 25.0 were utilized to analyze the data. Prior to main analyses, we conducted preliminary analyses, including checks for missing values, univariate and multivariate outliers, skewness and kurtosis coefficients, and descriptive statistics. To assess underlying factor structure of Turkish version of the MTS-A, we conducted confirmatory factor analyses (CFA). For criterion-related validity, we computed correlations between MTS-A and CYRM-12 total scores. For reliability, Cronbach's alpha and test-retest reliability coefficients of the MTS-A were calculated. In the research, we also cross-validated the psychometric properties of Turkish short version of the MTS-A and assessed measurement invariance across stages of adolescent development and gender. Finally, the research protocol was in compliance with American Psychological Association (APA) ethical guidelines. 


\section{Findings}

Descriptive findings demonstrated that boys $(M=53.89, s d=6.95)$ reported higher mental toughness than girls $(M=50.51, s d=7.35)\left(t_{(320)}=-4.230, p<.001\right)$. We also found that mental toughness levels of middle school students $(M=53.50, s d=7.52)$ were higher than high school $(M=51.27, s d=6.98)$ students $\left(t_{(320)}=2.765, p<\right.$ $.01)$. Preliminary analyses indicated that 18 -item six-factor original version of the MTS-A was confirmed in Turkish middle and high school data $\left(\chi^{2}{ }_{(129)}=217.412, p<.001, \chi^{2} / d f=1.69\right.$, CFI $=.96$, TLI $=.95$, AIC $=$ $301.412, \mathrm{BIC}=459.943, \mathrm{ECVI}=.939, \mathrm{RMSEA}=.05 \mathrm{CI}[.04, .06])$. Standardized factor loadings were above cut point of .30 and all were significant at .001 level. Furthermore, based on McGeown et al.'s (2018) expert views and suggestions, by choosing best exemplar items from each dimension, we constructed a brief 6-item Turkish version of the MTS-A. The results of CFA indicated that short form of the MTS-A provided perfect fit to the data $\left(\chi_{(9)}^{2}=8.198, p>.05, \chi^{2} / d f=.911, \mathrm{CFI}=1.00, \mathrm{TLI}=1.00, \mathrm{AIC}=32.198, \mathrm{BIC}=77.492, \mathrm{ECVI}=\right.$ $.100, \mathrm{RMSEA}=.00 \mathrm{CI}[.00, .06])$. The standardized factor loadings ranged from .31 to .78 and all were statistically significant at $p<.001$. The results of chi-squared difference test suggested that short form of the MTS-A had better model fit compared to 18-item long form of the MTS-A $\left(\Delta \chi_{(120, N=322)}^{2}=209.214, p<.001\right)$. In addition, short form of the MTS-A provided lower AIC, BIC, and ECVI values. Significant positive correlations between MTS-A and CYRM-12 total scores suggested that both short and long form of the MTS-A have criterion-related validity. Cronbach's alpha coefficients for MTS-A short and long form were .72 and .85, respectively. Further analyses regarding cross-validation and reliability study supported the psychometric properties of short form of the MTS-A in Turkish adolescent sample. In cross-validation study, hypothesized one-factor short form of the MTS-A provided good fit to the data set $\left(\chi^{2}{ }_{(9)}=17.230, p>.01, \chi^{2} / d f=1.91, \mathrm{CFI}=\right.$ $.96, \mathrm{TLI}=.94, \mathrm{RMSEA}=.06 \mathrm{CI}[.01, .09])$. The results of reliability study indicated that Cronbach's alpha and four-week test-retest reliability coefficients were .66 and .67 , respectively. The results of multiple group confirmatory factor analyses supported that short form of the MTS-A has configural and metric invariance across stages of adolescent development (early adolescence aged 11-14 years, middle adolescence aged 15-16 years, and late adolescence aged 17-18 years) and gender (boys and girls).

\section{Discussion and Conclusion}

In the present study, we conducted Turkish validation and construction of long and short form of the MTS-A. We investigated construct validity, criterion-related validity, reliability, cross-validation as well as measurement invariance of the MTS-A. Research results suggested that Turkish long and short form of the MTS-A is a valid and reliable measure to assess adolescents' attributes of mental toughness. In general, the present results were consistent with that of McGeown et al. (2018) who reported that MTS-A has good validity and reliability indices. In the present study, we found that boys reported greater mental toughness scores than girls. This finding was also consistent with previous research results (e.g., Crust et al., 2014; McGeown et al., 2018; St ClairThompson et al., 2017) highlighting the role of gender on mental toughness levels. In addition, we found that levels of mental toughness in high school students were lower compared to scores of middle school students. This finding differs from the results of McGeown et al. (2018) who reported that there is no significant association between age and mental toughness. One interpretation for this finding might be that as age and classroom level increases, Turkish students come across with greater academic pressure to pass school admission exams. In conclusion, it might be suggested that mental toughness is an important psychological resource for school children to deal with negative or challenging events as well as to pursuit goal-directed behaviors and become successful (Gucciardi et al., 2015; St Clair-Thompson, 2017). Future research might focus on highlighting the antecedents and outcomes of mental toughness in Turkish adolescents. Empirical findings might help researchers and practitioners to design evidence-based intervention and prevention programs that aim to enhance school children's attributes of mental toughness. It can be stated that Turkish long and short version of the MTS-A are valid and reliable measures to assess mental toughness in educational contexts. Nevertheless, further research is needed to ensure the psychometric robustness of the Turkish version of the MTS-A. 


\section{Giriş}

Bireylerin günlük yaşamda zorluklarla, baskılarla ve stres faktörleriyle nasıl başa çıktıklarına dair incelemeleri içeren zihinsel dayanıklılık (mental toughness) kavramı günümüzde hem ruh sağlığı alanında hem de okul ortamlarında giderek artan bir şekilde ele alınmaya başlanmıștır (St Clair-Thompson ve diğ., 2017). Alanyazındaki tanımlama ve açıklamalar, zihinsel dayanıklılı̆ıı pozitif psikolojinin kavramlarıyla ve zihinsel becerilerin kullanımıyla ilişkili olduğunu vurgulamaktadır (Connaughton, Hanton, Jones ve Wadey, 2008). Zihinsel dayanıklılı̆̆ı olumsuz ya da zorlayıcı olaylarla başa çıkmak için gerekli bir psikolojik özellik olduğu ileri sürülmektedir (Gucciardi, Hanton, Gordon, Mallett ve Temby, 2015). Bu psikolojik yapının daha iyi anlaşılması amacıyla araştırmacılar, zihinsel dayanıklılığın özelliklerini, nedenlerini, altında yatan süreçleri ve çıktılarını kavramsallaştırmaya çalışmaktadırlar (Sorensen, Schofield ve Jarden, 2016).

Zihinsel dayanıklılı̆ı̆ kavramsallaştırılması sürecinde, tek bir tanımlama yerine alanyazında farklı tanımlamaların olduğu görülmektedir. St Clair-Thompson ve diğerlerine (2015) göre zihinsel dayanıklılık, mevcut koşullara bakılmaksızın bireylerin yaşadıkları zorluk, stres ya da baskıyla nasıl başa çıktıklarına ilişkin bir kişilik özelliği olarak tanımlanmaktadır. Jin ve Wang'a (2018) göre zihinsel dayanıklılık, bireylerin zorlu yaşantılarla daha iyi başa çıkabilmelerini ve yüksek stres altında bile sağlıklı kalabilmelerini sağlayan bilişsel, davranışsal ve duygusal boyutları olan çok boyutlu psikolojik bir özelliğe işaret etmektedir. Zihinsel dayanıklılık, psikolojik sağlamlıkta (resilience) olduğu gibi zorluklarla başa çıkma kapasitesini ve zorlu yaşantılardan sonra kendini toparlama gücünü içermektedir (Jin ve Wang, 2018). Bununla birlikte, zihinsel dayanıklılık kavramı başa çıkma mekanizması olarak psikolojik sağlamlı̆̆ın da ötesinde azim, öz-yeterlik, özgüven ve motivasyon gibi psikolojik yapıları da içerisinde barındıran çok boyutlu şemsiye bir kavram olarak tanımlanmaktadır (Papageoriorgiou, Wong ve Clough, 2017). Gucciardi ve diğerlerine (2015) göre zihinsel dayanıklılık günlük yaşamdaki zorluklara, kötü olaylara ve stres faktörlerine rağmen bireylerin hedefleri doğrultusunda çabalamaya devam etmeleri, tüm bu güçlüklerle başa çıkmaları ve hatta büyüme, iyileşme ve gelişme eğilimleri göstermelerini içermektedir. McGeown, St Clair-Thompson ve Clough (2016), zihinsel dayanıklılı̆̆ın çocuk ve ergenlerin okul sonuçlarının (örneğin, okulda iyi oluş, akademik başarı, motivasyon, okul tükenmişliği vb.) önemli bir yordayıcısı olarak araştırmacılar ve uygulayıcılar için eğitim alanında yararlı bir çerçeve sunabileceğini belirtmektedirler. Zihinsel dayanıklılığı incelemek için kullanılan farklı modeller olmasına rağmen, eğitim alanında en yaygın kullanılan modelde altı özellik öne çıkmaktadır: Zorluklarla mücadele etme, kişilerarası yeteneklere güvenme, bireysel yeteneklere güvenme, duyguları kontrol etme, yaşamı kontrol etme ve kendini adama (McGeown, St Clair-Thompson ve Putwain, 2018). Alanyazında, zihinsel dayanıklılık düzeyi yüksek olan öğrencilerin, sosyal ortamlarda kendine güvenme, yeteneklerine güvenme, öfke, üzüntü, kaygı, stres gibi duyguları düzenleyebilme, yaşamındaki olayların kendi kontrolünde olduğunu düşünme, zorluklarla karşılaştığında mücadele etme, yeni ve zorlayıcı görevleri denemekten mutlu olma gibi özellikler gösterdikleri belirtilmektedir (örn. Gucciardi ve diğ., 2015; McGeown ve diğ., 2016; McGeown ve diğ., 2018).

Alanyazında ampirik bulgular, zihinsel dayanıklılığın bireylerin psikolojik uyum süreçlerini ve okul sonuçlarını anlamlı bir biçimde yordadığını göstermektedir. Örneğin, Sağkal ve Özdemir (2019) ergenlerle gerçekleştirdikleri çalışmalarında, yüksek zihinsel dayanıklılık düzeyinin yüksek öznel mutluluk ve düşük psikolojik sıkıntıyla iliş̧kili olduğunu bulmuşlardır. Benzer bir biçimde, McGeown ve diğerleri (2018) zihinsel dayanıklılığın ergenlerde daha düşük depresyon ve kaygıyı yordadığını rapor etmişlerdir. Üniversite öğrencilerinde zihinsel dayanıklılığın bağlanma ve psikolojik iyilik haliyle ilişkisinin incelendiği bir başka araştırmada, kaygılı bağlanma ve psikolojik iyi oluş arasındaki ilişkide zihinsel dayanıklılığın aracılık etkisinin olduğu sonucuna ulaşılmıştır (Jin ve Wang, 2018). Zihinsel dayanıklılık ile okul sonuçları arasındaki ilişkilerin incelendiği bir çalışmada (St Clair-Thompson ve diğ., 2015) ise zihinsel dayanıklılık ile akademik ilerleme, okula devam, olumlu sınıf içi davranışlar sergileme ve akran ilişskileri gibi değişkenler arasında anlamlı ilişkiler saptanmıştır. Ayrıca, araştırma bulguları (örn. Crust ve diğ., 2014; St. Clair-Thompson ve diğ., 2017) zihinsel dayanıklılı̆̆ın lise ve üniversiteye geçiş sürecinde öğrencilerin uyum sürecini kolaylaştırdığını göstermektedir. Sağkal (2019) ise 14-18 yaşlarındaki lise öğrencileriyle yürüttüğü çalışmasında, zihinsel dayanıklıllı̆ın okul katılımını arttırdığını, okul tükenmişliğini ise azalttığını tespit etmiştir. Dolayısıyla, tüm bu araçları sonuçları, zihinsel dayanıklılık düzeyinin gerek öğrencilerin bireysel psikolojik uyumları gerekse de okul sonuçları üzerinde anlamlı etkilere sahip olduğunu göstermektedir.

Yaşamın içerisinde farklı bağlamlarda deneyimlenen rekabet ve baskı unsurları dikkate alındığında, çok boyutlu şemsiye bir kavram olarak ele alınan zihinsel dayanıklılık, bireylerin psikolojik uyum süreçlerini koruyucu ve güçlendirici işleviyle önemli bir araştırma ve müdahale alanı olarak gözükmektedir. Özellikle, okul bağlamında ele alındığında, öğrencilerin okula uyum, kişilerarası ilişkiler kurma, kişisel ve eğitsel zorluklar ve sorunlarla başa çıkma, akademik hedefler belirleme ve bu hedeflere adanma, duygu durumlarını düzenleyebilme gibi psikososyal gelişimleriyle ilgili önemli becerilere ihtiyaç duydukları açıktır. Ortaokul ve lise düzeyleri dikkate alındığında, ergen gelişiminde kişilik özelliklerinin desteklenmesinin önemli olduğu vurgulanmaktadır (Santrock, 2012). Dolayısıyla, çok boyutlu bir kişilik özelliği olarak zihinsel dayanıklılığın öncüllerinin, 
sonuçlarının ve hatta bu ilişkilerde aracı ve düzenleyici mekanizmaların okul ortamlarında incelenmesinde yarar vardır. Ampirik bulgulara dayanarak, zihinsel dayanıklılığı güçlendirmeye yönelik okul temelli müdahale programlarının geliştirilmesi, uygulanması ve etkililiğinin test edilmesi gerekmektedir. Bu bağlamda, gerek araştırma alanında gerekse de sahada belirtilen tüm bu çalışmaların gerçekleşebilmesi için öncelikle bu psikolojik yapıyı geçerli, güvenilir ve kullanışlı bir biçimde ölçebilecek ölçme araçlarının araştırmacılar tarafından alanyazına kazandırılması hedeflenmelidir. Dolayısıyla, bu araştırmada, McGeown ve diğerleri (2018) tarafindan geliştirilen Ergenler İçin Zihinsel Dayanıklılık Ölçeği'nin (EİZDÖ) Türkçe'ye uyarlanması, geçerlik ve güvenirliğinin incelenmesi amaçlanmıştır. Bunun yanı sıra, mevcut araştırmada, EIZZDÖ’nden elde edilen bulgular betimsel açıdan değerlendirilmiş, zihinsel dayanıklılık düzeyinin cinsiyete ve okul düzeyine göre farklılaşıp farklılaşmadığı test edilmiştir.

\section{Yöntem}

\section{Katılımellar}

Araştırmada iki ayrı örneklem grubundan veri toplanmıştır. Birinci örneklem grubundan elde edilen veriler üzerinde hedef ölçme aracının geçerlik (yapı geçerliği ve ölçüt-bağıntılı geçerlik) ve güvenirlik (Cronbach alfa katsayısı) analizleri gerçekleştirilirken; ikinci örneklem grubunda hedef ölçme aracının çapraz geçerlik (yapı geçerliği) ve güvenirlik (Cronbach alfa katsayısı ve test-tekrar test güvenirliği) düzeyi incelenmiştir. Birinci örneklem grubu için araştırmanın katılımcılarını, Aydın ili Efeler merkez ilçesinde çok aşamalı küme örnekleme yöntemiyle ulaşılan ortaokul ve lise öğrencileri oluşturmuştur. Araştırmada toplam 357 katılımcı (162 kız, \% 45.4; 195 erkek, \%54.6) yer almıştır. Katılımcıların \% 13.7'sini altıncı sınıf, \%19'unu yedinci sınıf, \% 15.7'sini sekizinci sınıf, \%11.2'sini dokuzuncu sinıf, \%8.1'ini onuncu sinıf, \%9'unu on birinci sinıf ve \% 23.2'sini on ikinci sınıf öğrencileri oluşturmuştur. Katılımcıların yaşları 11 ile 18 arasında $(O r t=14.92$; ss $=2.09)$ değişmiştir. Katılımcıların çoğunluğunda anne (\% 68.1) ve babaların (\% 63) eğitim düzeyleri lise ve altı olarak belirlenmiş̧ir. Katılımcıların ailelerinin aylık ortalama gelirinin 4000TL-5000TL aralığında olduğu belirlenmiş̧ir. Katılımcıların \% 91'i anne-baba ve çocukların birlikte yaşadığı ailelerden gelmiştir. Demografik veriler, araştırma katılımcılarının büyük bir çoğunluğunun alt ve orta sosyo-ekonomik düzey ailelerden geldiğini göstermiştir. Araştırmanın ikinci örneklem grubunu, Aydın ili Efeler ilçesi merkez okul bölgesindeki ortaokul ve liselerden çok aşamalı küme örnekleme yöntemiyle ulaşılan öğrenciler oluşturmuştur. İkinci örneklem grubunda, toplam 307 katılımcı (146 kız, \% 47.6; 161 erkek, \% 52.4) yer almıştır. Katılımcıların yaşları 11 ile 18 arasında $(O r t=14.97 ; s s=1.55)$ değişmiştir. Birinci örneklem grubuna benzer bir biçimde anne (\% 84) ve babaların (\% 77.5) büyük çoğunluğunun lise ve altı düzey eğitime sahip oldukları, aylık ortalama aile gelirinin 4000TL5000TL aralı̆̆ında olduğu ve katılımcıların \% 87'sinin anne-baba ve çocukların birlikte yaşadıkları ailelerden geldiği tespit edilmiştir.

\section{Veri Toplama Araçları}

Ergenler İçin Zihinsel Dayanıklılık Ölçeği (EiZZDÖ). Ergenler İçin Zihinsel Dayanıklılık Ölçeği (Mental Toughness Scale for Adolescents, MTS-A), 11-18 yaş ergenlerin zihinsel dayanıklılık düzeylerini ölçmek amacıyla McGeown ve diğerleri (2018) tarafindan geliştirilmiş̧ir. Ölçek, 18 maddeden ve altı alt boyuttan oluşmaktadır. Orijinal çalışmada alt boyutlar, zorluklarla mücadele etme, kişilerarası yeteneklere güvenme, bireysel yeteneklere güvenme, duyguları kontrol etme, yaşamı kontrol etme ve kendini adama olarak tanımlanmıştır. EİZDÖ'nin her bir alt boyutunda üçer madde yer almaktadır. Ölçekteki maddeler 4'lü Likert derecelendirme anahtarı $(1$ = kesinlikle katılmıyorum, $4=$ kesinlikle katıllyorum $)$ üzerinde yanıtlanmaktadır. Orijinal çalışmada, açımlayıcı faktör analiziyle belirlenen altı faktörlü yapı, doğrulayıcı faktör analizinde veri setine iyi uyum sağlamıştır. Cronbach alfa katsayıları alt boyutlar için .73 ile .79 arasında değişmiştir. EIZDÖ'nden elde edilen yüksek puanlar, daha yüksek akademik motivasyon, okul katılımı ve daha düşük kayg1 ve depresyonla ilişkili bulunmuştur. Araştırma bulguları, okullarda 11-18 yaş ergenlerin zihinsel dayanıklılık düzeylerinin ölçümünde EİZDÖ'nin güçlü psikometrik özelliklere sahip olduğunu göstermiştir (McGeown ve diğ., 2018).

Çocuk ve Genç Psikolojik Sağlamlık Ölçeği (ÇGPSÖ-12). Mevcut araştırmada, ergenlerin psikolojik sağlamlık düzeylerini ölçmek amacıyla Çocuk ve Genç Psikolojik Sağlamlık Ölçeği (ÇGPSÖ-12) kullanılmıştır. Kısa formu Liebenberg, Ungar ve LeBlanc (2013) tarafindan geliştirilen ÇGPSÖ-12, Arslan (2015) tarafindan Türkçe'ye uyarlanmıştır. ÇGPSÖ-12, toplamda 12 maddeden ve tek boyuttan oluşmaktadır. Ölçekteki maddeler 5'li Likert derecelendirme anahtarı $(1=$ Beni hiç tanımlamıyor; $5=$ Beni tamamen tanımllyor $)$ üzerinde yanıtlanmaktadır. Ölçekten alınan yüksek puanlar, psikolojik sağlamlık düzeyinin artı̧̧ıı göstermektedir. Arslan (2015), 11-16 yaş örneklemde ölçeğin güvenirlik katsayısını .91 olarak rapor etmiştir. Mevcut çalışmada, ÇGPSÖ-12'nin Cronbach alfa katsayıs1 .84 olarak hesaplanmıştır.

Demografik Bilgi Formu (DBF). Araştırmada, katılımcılar cinsiyet, yaş, sınıf düzeyi, ebeveyn eğitim durumu, aylık ortalama aile geliri ve aile yapısına ilişkin soruları içeren kısa bir DBF doldurmuşlardır. 


\section{Veri Analizi}

Araştırma verilerinin analizinde SPSS 25.0 ve AMOS 25.0 programları kullanılmıştır. Kayıp değerlerin bulunmadığı veri setlerinde öncelikle tek değişkenli ve çok değişkenli uç değerlerin etkisi incelenmiştir. Araştırmanın birinci örneklemine ait veri setinde standardize edilmiş $z$ puanları \pm 3.29 'un üzerinde bulunan toplam 10 katılımcı ile Mahalanobis uzaklığı .001 düzeyinde anlamlı toplam 25 katılımcıya ait gözlem değeri analiz dışı tutulmuştur. Ayrıca, -.841 ile .430 arasında değişen çarpıklık katsayıları ile -.793 ile .468 arasında değişen basıklık katsayıları maddelerin veri setinde normal dağıldığını göstermiştir (Tabachnick ve Fidell, 2007). Toplam 322 katılımcının verilerinin analize dâhil edildiği birinci örneklem grubunda, ilk olarak betimsel istatistikler incelenmiştir. EIZZDÖ'nden elde edilen toplam puanların cinsiyete ve okul düzeyine (ortaokul ve lise) göre farklılaşıp farklılaşmadığını tespit etmek için bağımsız örneklemler için $t$-testi uygulanmıştır. Analizlerde tespit edilen anlamlı farklılıkların etki büyüklügünü saptamak için Cohen'in $d$ katsayısı hesaplanmıştır (Green ve Salkind, 2005). EİZDÖ'nin orijinal uzun ve oluşturulan kısa formunun yapı geçerliğini incelemek için doğrulayıcı faktör analizi (DFA) uygulanmıştır. EİZDÖ'nin uzun ve kısa formlarının ölçüt-bağıntılı geçerliğini incelemek için hedef ölçme aracı ile Çocuk ve Genç Psikolojik Sağlamlık Ölçeği’nden (ÇGPSÖ-12; Arslan, 2015; Liebenberg ve diğ., 2013) elde edilen puanlar arasındaki Pearson momentler çarpımı korelasyon katsayıları hesaplanmıştır. EİZDÖ’nin güvenirlik düzeyini belirlemek için Cronbach alfa katsayısı incelenmiştir. Araştırmada, EİZDÖ'nin kısa formunun çapraz geçerlik ve güvenirliğini belirlemek için ikinci bir örneklem grubundan veri toplanmıştır. Çapraz geçerlik ve güvenirlik analizleri öncesinde veri seti incelenmiştir. Veri setinde kayıp değerlerin bulunmadığı gözlenmiştir. Standardize edilmiş $z$ puanı \pm 3.29 'un üzerinde bulunan bir katılımcı ile Mahalanobis uzaklığı 001 düzeyinde anlamlı toplam 4 katılımcıya ait gözlem değeri analiz dışı tutulmuştur. Araştırmada 302 katılımcıya ait veri seti üzerinde geçerlik ve güvenirlik analizleri gerçekleştirilmiştir. EIZZDÖ'nin kısa formunda yer alan maddelerin önerilen faktör yapısını ne kadar iyi temsil ettiğini belirlemek için birinci düzey DFA gerçekleştirilmiştir. EIZZÖ'nin kısa formunun güvenirlik analizleri kapsamında Cronbach alfa katsayısı ile test-tekrar test güvenirlik katsayısı hesaplanmıştır. Araştırmada, DFA model uyumlarının değerlendirilmesinde ki-karenin serbestlik derecesine oranı $\left(\chi^{2} / s d\right)$, Karşılaştırmalı Uyum İndeksi (CFI), Tucker-Lewis İndeksi (TLI) ve Yaklaşık Hataların Ortalama Karekökü (RMSEA) dikkate alınmıştır (Çokluk, Şekercioğlu ve Büyüköztürk, 2010). Modeller arası karşılaştırmalarda ise ki-kare fark testi ile Akaike'nin Bilgi Ölçütü (AIC), Bayes Bilgi Ölçütü (BIC) ve Beklenen Çapraz Geçerlik İndeksi (ECVI) dikkate alınmıştır (Byrne, 2010). Çokluk ve diğerlerine (2010) göre, $\chi^{2} / s d \leq 2$, CFI $\geq .95$, TLI $\geq .95$ ve RMSEA $\leq .05$ mükemmel uyum iyiliği değerlerini temsil etmektedir. Ayrıca, $.05<$ RMSEA $\leq .08$ ile $.90 \leq$ TLI $<.95$ aralığındaki değerler iyi uyumun göstergeleri olarak kabul edilmektedir (Çokluk ve diğ., 2010). Modeller arası karşılaştırmalarda ise daha düşük AIC, BIC ve ECVI değerleri çapraz geçerliğin göstergeleri olarak değerlendirilmektedir (Byrne, 2010). Ayrıca, araştırmada, EIZDÖ’nin ergenliğin gelişim aşamalarına (ilk ergenlik, orta ergenlik ve ileri ergenlik) ve cinsiyete (kız ve erkek) göre ölçme değişmezliğini incelemek için çoklu grup doğrulayıcı faktör analizleri gerçekleştirilerek yapısal (configural) ve metrik değişmezlik (metric invariance) test edilmiştir. Ölçme değişmezliğine ilişkin sonuçların değerlendirilmesinde Chen'in (2007) önerdiği $\Delta$ CFI $<.01$ ve $\Delta$ RMSEA $<.015$ ölçütleri dikkate alınmıştır.

\section{İșlem Yolu}

Araştırmada öncelikle EIZZDÖ'nin Türkçe'ye uyarlanabilmesi için McGeown ve diğerlerinden (2018) izin alınmıştır. Hedef ölçeğin Türkçe'ye çevirisinde ileri ve geri çeviri işlemleri gerçekleştirilmiştir. İlk olarak, araştırmanın yazarları tüm maddeleri birbirlerinden bağımsız olarak Türkçe'ye çevirmişler ve ardından tüm çevirilerin sentezlenmesini sağlamışlardır. Bir sonraki adımda, hem İngilizce hem de Türkçe'ye hâkim iki alan uzmanı, araştırma ekibi tarafından sentezlenen Türkçe çevirileri yeniden orijinal dile çevirmişlerdir. Geri çeviriler ve orijinal maddeler arasındaki tutarlılığı incelemek amacıyla McGeown ve diğerlerinden (2018) uzman görüşleri alınmıştır. Uzman görüşleri doğrultusunda çeviriler yeniden düzenlenmiş ve McGeown ve diğerlerinin (2018) önerileri doğrultusunda nihai ölçek formu oluşturulmuştur. Çeviri işlemlerinin sonrasında, Aydın İl Milli Eğitim Müdürlüğü'nden alınan yasal/etik araştırma izniyle birlikte hedef ölçeğin geçerlik ve güvenirlik çalışmaları için veri toplama işlemlerine geçilmiştir. Araştırmaya Aydın ili Efeler ilçesi merkez okul bölgesindeki ortaokul ve liselerde okuyan 11-18 yaş öğrenciler, ders saati içerisinde, bilgilendirilmiş onam, gizlilik ve gönüllülük ilkeleri doğrultusunda katılmışlardır. Çalışmanın veri toplama işlemleri, araştırmanın yazarları tarafından 2017-2018 eğitim öğretim yılının ikinci döneminde gerçekleştirilmiştir.

\section{Bulgular}

\section{Betimleyici Bulgular}

Araştırmada, katılımcıların EIZZDÖ'nden aldıkları toplam puanlar 34 ile 72 arasında değişmiş ve ortalama puan $52.34(s s=7.32)$ olarak hesaplanmıştır. Basıklık $(.081)$ ve çarpıklık (-.084 ) katsayıları, EİZDÖ'ne ait toplam puanların normal dağılıma sahip olduğunu göstermiştir. Bağımsız örneklemler için $t$-testi sonuçları $\left(t_{(320)}=-\right.$ 
4.230, $p<.001)$, erkek öğrencilerin $(O r t=53.89, s s=6.95)$ k1z öğrencilere $(O r t=50.51, s s=7.35)$ göre daha yüksek zihinsel dayanıklılık düzeyi rapor ettiklerini göstermiştir. Ayrıca, bu gruplar arası farklılığın etki büyüklüğünün (Cohen's $d=.47$ ) küçük olduğu belirlenmiştir (Green ve Salkind, 2005). Araştırma verileri okul düzeyi açısından incelendiğinde ise ortaokul öğrencilerinin zihinsel dayanıklılık düzeylerinin $($ Ort $=53.50, s s=$ 7.52) lise öğrencilerine $(O r t=51.27, s s=6.98)$ göre anlamlı düzeyde daha yüksek olduğu görülmüştür $\left(t_{(320)}=\right.$ $2.765, p<.01)$. Ayrıca, bu bulgunun küçük bir etki büyüklüğüne (Cohen's $d=.31$ ) sahip olduğu belirlenmiştir (Green ve Salkind, 2005).

\section{EİZDÖ’nin Geçerliğine İlişkin Bulgular}

Yapı Geçerliğine İlişkin Bulgular. EİZDÖ'nin 18 maddeli, altı boyutlu orijinal faktör yapısını hedef örneklemde test etmek için AMOS 25.0 programı kullanılarak doğrulayıcı faktör analizi (DFA) gerçekleştirilmiştir. Altı faktörlü ikinci düzey DFA sonucunda, hipotez model veri setine mükemmel uyum sağlamıştır: $\chi^{2}(129)=$ $217.412, p<.001, \chi^{2} / s d=1.69, \mathrm{CFI}=.96, \mathrm{TLI}=.95, \mathrm{AIC}=301.412, \mathrm{BIC}=459.943, \mathrm{ECVI}=.939, \mathrm{RMSEA}=$ .05 CI [.04, .06]. Bu bulgu, EİZDÖ'nin McGeown ve diğerleri (2018) tarafindan önerilen altı faktörlü orijinal yapısının Türkiye'de 11-18 yaş ergen örnekleminde doğrulandığını göstermiştir. Araştırmada, hipotez modele ilişkin standardize edilmiş faktör yükleri Tablo 1'de verilmiştir. Faktör yükleri zorluklarla mücadele etme boyutunda .33 ile .85 , kişilerarası yeteneklere güvenme boyutunda .41 ile .80 , bireysel yeteneklere güvenme boyutunda .79 ile .88 , duyguları kontrol etme boyutunda .43 ile .81 , yaşamı kontrol etme boyutunda .49 ile .63 ve son olarak kendini adama boyutunda .64 ile .85 arasında değişmiştir. Ayrıca, ikinci düzey standardize edilmiş faktör yüklerinin .36 ile .90 arasında değiştiği tespit edilmiştir. Birinci ve ikinci düzey tüm parametre tahminlerinin $p<.001$ düzeyinde anlamlı olduğu görülmüştür.

Tablo 1 EİZDÖ Maddeler, Faktörler ve Standardize Edilmiş Faktör Yükleri $(N=322)$

\begin{tabular}{|c|c|c|c|c|c|c|c|}
\hline \multirow[t]{2}{*}{ Maddeler } & \multicolumn{6}{|c|}{$\begin{array}{c}\text { Faktörler (F) ve } \\
\text { Standardize Edilmiş Faktör Yükleri }\end{array}$} & \multirow[b]{2}{*}{ SH } \\
\hline & F1 & F2 & F3 & $\mathrm{F} 4$ & F5 & F6 & \\
\hline Zorlayıcı şeyleri denemek her zaman iyidir. & $.67^{* * *}$ & & & & & & .03 \\
\hline Yeni ve zorlayici görevleri denemekten mutlu olurum. & $.85^{* * * *}$ & & & & & & .03 \\
\hline Zorluklar potansiyelimi açığa çıkarır. & $.33^{* * * *}$ & & & & & & .04 \\
\hline Tanımadığım insanlarla bir aradayken gergin olurum. & & $.41^{* * *}$ & & & & & .06 \\
\hline Sosyal ortamlarda kendime güvenirim. & & $.80^{* * * *}$ & & & & & .03 \\
\hline Başka insanların önünde konuşurken kendime güvenirim. & & $.72^{* * *}$ & & & & & .04 \\
\hline Yeteneklerime güvenirim. & & & $.79^{* * * *}$ & & & & .02 \\
\hline Genellikle, yeteneklerime güvenmem. & & & $.87^{* * *}$ & & & & .02 \\
\hline Genellikle, yeteneklerime güvenirim. & & & $.88^{* * *}$ & & & & .01 \\
\hline $\begin{array}{l}\text { Bazen duygularım (örneğin, öfke, üzüntü, endişe) beni } \\
\text { kontrol altına alır. }\end{array}$ & & & & $.43^{* * * *}$ & & & .05 \\
\hline Öfkemi/üzüntümü/stresimi durdurmak benim için zordur. & & & & $.81^{* * * *}$ & & & .07 \\
\hline $\begin{array}{l}\text { Olumsuz duyguları yönetmekte iyiyimdir (örneğin, öfke, } \\
\text { üzüntü, endise). }\end{array}$ & & & & $.72^{* * * *}$ & & & .06 \\
\hline $\begin{array}{l}\text { Eğer çok çalışırsam, geleceğim nasıl olmasını istiyorsam } \\
\text { öyle olabilir. }\end{array}$ & & & & & $.49^{* * * *}$ & & .04 \\
\hline Gelecek yaşantımda ne olacağını kontrol edemem. & & & & & $.60^{* * * *}$ & & .04 \\
\hline $\begin{array}{l}\text { Yaşamımda olan her şeyin benim kontrolümde olduğunu } \\
\text { hissederim. }\end{array}$ & & & & & $.63^{* * * *}$ & & .05 \\
\hline Bask1 altında olduğumda pes ederim. & & & & & & $.64^{* * * *}$ & .03 \\
\hline Çoğu şeyi yarım bırakırım. & & & & & & $.67^{* * * *}$ & .03 \\
\hline Zorluklarla karșılaștığımda, genellikle vazgeçerim. & & & & & & $.85^{* * *}$ & .02 \\
\hline
\end{tabular}

Not. $^{* * *} p<.001 ; \mathrm{F} 1=$ zorluklarla mücadele etme, F2 = kişilerarası yeteneklere güvenme, F3 = bireysel yeteneklere güvenme, F4 = duygular1 kontrol etme, F5 = yaşamı kontrol etme, F6 = kendini adama; $S H=$ faktör yüklerinin standart hatası

Ayrıca, bu araştırmada, McGeown ve diğerlerinin (2018) uzman görüşleri doğrultusunda her bir boyutta o boyutu en iyi temsil eden birer madde seçilerek EİZÖ’nin altı maddeli kısa formu oluşturulmuş ve bu formun yapı geçerliği incelenmiştir. EIZDÖ’nin altı maddeli tek boyutlu kısa formu DFA'nde veri setine mükemmel uyum göstermiştir: $\chi^{2}(9)=8.198, p>.05, \chi^{2} / s d=.911, \mathrm{CFI}=1.00, \mathrm{TLI}=1.00, \mathrm{AIC}=32.198, \mathrm{BIC}=77.492$, $\mathrm{ECVI}=.100, \mathrm{RMSEA}=.00 \mathrm{CI}[.00, .06]$. EIZZÖ’nin kısa formuna ilişkin standardize edilmiş faktör yüklerinin $p<.001$ düzeyinde anlamlı olduğu ve .31 ile .78 arasında değiştiği belirlenmiştir (bkz. Tablo 2). Ki-kare fark testi sonuçları, EIZDÖ'nin altı maddeli tek boyutlu kısa formunun, 18 maddeli altı boyutlu uzun forma göre daha iyi bir model uyumuna sahip olduğunu göstermiştir: $\Delta \chi^{2}(120, N=322)=209.214, p<.001$. Ayrıca, EİZDÖ’nin kısa formuna ilişkin hipotez modelin, altı faktörlü orijinal modele göre daha düşük AIC, BIC ve ECVI değerleri 
gösterdiği tespit edilmiştir. Tüm bu bulgular, EİZDÖ’nin kısa formunun 18 maddeli altı boyutlu uzun forma göre daha güçlü bir psikometrik yapıya sahip olduğunu göstermiştir.

Tablo 2

EİZDÖ Kısa Formu ve Standardize Edilmis Faktör Yükleri $(N=322)$

\begin{tabular}{|c|c|c|}
\hline Maddeler & $\begin{array}{l}\text { Standardize Edilmiş } \\
\text { Faktör Yükleri }\end{array}$ & SH \\
\hline Yeni ve zorlayıcı görevleri denemekten mutlu olurum. & $.66^{* * * *}$ & .03 \\
\hline Öfkemi/üzüntümü/stresimi durdurmak benim için zordur. & $.31^{* * * *}$ & .06 \\
\hline Yaşamımda olan her şeyin benim kontrolümde olduğunu hissederim. & $.40^{* * * *}$ & .04 \\
\hline Sosyal ortamlarda kendime güvenirim. & $.63^{* * *}$ & .03 \\
\hline Zorluklarla karşılaştığımda, genellikle vazgeçerim. & $.66^{* * * *}$ & .03 \\
\hline Genellikle, yeteneklerime güvenirim. & $.78^{* * * *}$ & .03 \\
\hline
\end{tabular}

Not. $^{* * *} p<.001 ; S H=$ faktör yüklerinin standart hatası

Ölçüt-Bağıntılı Geçerliğe Illişkin Bulgular. Araştırmada, EİZDÖ uzun ve kısa formunun ölçüt-bağıntılı geçerliğini incelemek için çalışmanın katılımcılarına Çocuk ve Genç Psikolojik Sağlamlık Ölçeği (ÇGPSÖ-12; Arslan, 2015; Liebenberg ve diğ., 2013) uygulanmıştır. Ölçüt-bağıntılı geçerlik için EİZDÖ ile ÇGPSÖ-12 arasındaki Pearson momentler çarpımı korelasyon katsayıları hesaplanmıştır. Beklendiği üzere (bkz. Tablo 3), EİZÖ̈nin alt boyutları ile ÇGPSÖ-12 arasında pozitif yönde, orta düzeyde anlamlı $(p<.01)$ ilişkiler saptanmıştır. Pearson momentler çarpımı korelasyon katsayıları .29 ile .52 arasında değişmiştir. Ayrıca, EIZZDÖ kısa form ile ÇGPSÖ-12 $(r=.55, p<.01)$ ve EİZDÖ uzun form ile ÇGPSÖ-12 $(r=.56, p<.01)$ arasında pozitif yönde, orta düzeyde anlamlı ilişkiler tespit edilmiştir. Analizlerde, cinsiyet ve okul düzeyi (ortaokul-lise) kontrol değişkeni olarak alındığında EİZDÖ ile ÇGPSÖ-12 arasındaki korelasyonlara ilişkin örüntülerin değişmediği gözlenmiştir. Tüm bu bulgular, EİZDÖ’nin kısa ve uzun formunun ölçüt-bağıntılı geçerliğe sahip olduğunu göstermektedir.

Tablo 3

EİZD̈̈ Uzun ve Kısa Form'a İlişkin Betimsel İstatistikler ve Ölçüt-Bağıntılı Geçerlik Korelasyonları

\begin{tabular}{lccc}
\hline & Ort & $s s$ & ÇGPSÖ-12 ile korelasyonlar \\
\hline Zorluklarla mücadele etme & 9.10 & 1.64 & $.37^{* * *}$ \\
Kişilerarası yeteneklere güvenme & 8.26 & 1.97 & $.34^{* * *}$ \\
Bireysel yeteneklere güvenme & 9.67 & 1.89 & $.52^{* *}$ \\
Duyguları kontrol etme & 7.05 & 2.06 & $.29^{* *}$ \\
Yaşamı kontrol etme & 8.86 & 1.66 & $.33^{* *}$ \\
Kendini adama & 9.40 & 1.83 & $.37^{* *}$ \\
EİZDÖ Uzun Form Toplam Puan & 52.34 & 7.31 & $.56^{* *}$ \\
EİZDÖ Kisa Form Toplam Puan & 17.56 & 2.99 & $.55^{* *}$ \\
\hline
\end{tabular}

\section{EİZDÖ’nin Güvenirliğine İlişskin Bulgular}

Araştırmada, EİZDÖ’nin alt boyutlarına ilişkin kabul edilebilir iç tutarlık düzeyleri tespit edilmiştir. Cronbach alfa katsayıları, zorluklarla mücadele etme alt boyutu için .61, kişilerarası yeteneklere güvenme alt boyutu için .67 , bireysel yeteneklere güvenme alt boyutu için .88, duyguları kontrol etme alt boyutu için .68, yaşamı kontrol etme alt boyutu için .60 ve kendini adama alt boyutu için .76 olarak hesaplanmıştır. EİZDÖ'nin kısa formunun Cronbach alfa katsayısı .72; uzun formunun Cronbach alfa katsayısı ise .85 olarak belirlenmiştir. Tüm bu bulgular, EİZDÖ’nin kısa ve uzun formunun yeterli iç tutarlığa sahip olduğunu göstermektedir.

\section{EİZDÖ Kısa Formu'nun Çapraz Geçerlik ve Güvenirlik Bulguları}

Araştırmada, EİZÖ kısa formunun çapraz geçerlik ve güvenirliğini incelemek için ikinci bir örneklem grubundan veri toplanmıştır. Yaşları 11 ile 18 arasında $(O r t=14.97$; ss $=1.55)$ değişen toplam 307 katılımcı (146 kız, \% 47.6; 161 erkek, \% 52.4) çalışmada yer almıştır. Mevcut araştırmada, ilk çalışmada oluşturulan EİZÖ'nin altı maddeli tek boyutlu kısa formunun ikinci bir örneklem grubundan elde edilen DFA sonuçları, hipotez modelin veri setine iyi uyum sağladığını göstermiştir: $\chi^{2}(9)=17.230, p>.01, \chi^{2} / s d=1.91$, CFI $=.96$, TLI $=.94$, RMSEA $=.06$ CI $[.01, .09]$. EIZZDÖ'nin kısa formuna ilişkin standardize edilmiş faktör yüklerinin $p<$ .001 düzeyinde anlamlı olduğu ve .35 ile .69 arasında değiștiği görülmüştür (bkz. Tablo 4). Güvenirlik analizleri, EİZÖ kısa formunun Cronbach alfa katsayısının .66 olduğunu göstermiştir. Ayrıca, dört hafta arayla toplam 69 katılımcıyla gerçekleştirilen test-tekrar test güvenirlik çalışmasında, güvenirlik katsayısı .67 $(p<.01)$ olarak hesaplanmıştır. Sonuç olarak bu bulgular, EİZDÖ’nin kısa formunun çapraz geçerliğe ve güvenirliğe sahip olduğunu göstermiştir. 
EIZDÖ Kısa Formuna İlişkin Çapraz Geçerlik ve Güvenirlik Sonuçları $(N=302)$

\begin{tabular}{lcc}
\hline Maddeler & $\begin{array}{c}\text { Standardize Edilmiş } \\
\text { Faktör Yükleri }\end{array}$ & $S H$ \\
\hline Yeni ve zorlayıcı görevleri denemekten mutlu olurum. & $.53^{* * *}$ & .04 \\
Öfkemi/üzüntümü/stresimi durdurmak benim için zordur. & $.40^{* * *}$ & .06 \\
Yaşamımda olan her şeyin benim kontrolümde olduğunu hissederim. & $.35^{* * *}$ & .05 \\
Sosyal ortamlarda kendime güvenirim. & $.48^{* * *}$ & .04 \\
Zorluklarla karşılaştığımda, genellikle vazgeçerim. & $.69^{* * *}$ & .03 \\
Genellikle, yeteneklerime güvenirim. & $.61^{* * *}$ & .03 \\
Cronbach alfa katsayısı & .66 \\
Test-tekrar test güvenirlik katsayıs1 & .67 \\
Ortalama & & 17.87 \\
Standart sapma & & 2.71 \\
Ranj & & $10-24$ \\
\hline Not. ${ }^{* * *} p<.001 ; S H=$ faktör yüklerinin standart hatası & &
\end{tabular}

\section{EİZDÖ Kısa Formu'na İlişkin Çoklu Grup Doğrulayıcı Faktör Analizleri}

Araştırmada, EİZDÖ kısa formunun ergenliğin gelişim aşamalarına ve cinsiyete göre ölçme değişmezliğine sahip olup olmadığını incelemek için çoklu grup doğrulayıcı faktör analizleri gerçekleştirilmiştir. Analizler için gerekli örneklem büyüklüğünü sağlamak için birinci ve ikinci örneklem gruplarından elde edilen veriler birleştirilmiştir $\left(N_{\text {toplam }}=624\right)$. Araştırmada, EİZDÖ kısa formunun ergenliğin gelişim aşamalarına (ilk ergenlik [11-14 yaş], orta ergenlik [15-16 yaş] ve ileri ergenlik [17-18 yaş]) göre yapısal (configural invariance) ve metrik değişmezliği (metric invariance) incelenmiştir. Parametrelerin serbestçe tahmin edildiği yapısal model ile faktör yüklerinin gruplar arası eşitliğinin sağlandığı metrik modelin veri setine mükemmel uyum sağladığg görülmüştür. Yapısal model için uyum iyiliği değerleri $\chi^{2}(27)=35.491, p>.05, \chi^{2} / s d=1.314, \mathrm{CFI}=.985, \mathrm{RMSEA}=.023 \mathrm{CI}$ $[.00, .04]$ iken metrik modelin uyum iyiliği değerleri $\chi^{2}(24)=51.801, p>.05, \chi^{2} / s d=1.328$, CFI $=.978$, RMSEA = .023 CI [.00, .04] olarak belirlenmiştir. Yapısal modelin veri setine mükemmel uyum sağlaması, ölçme aracının ergenliğin gelişim aşamalarına göre yapısal değişmezliğe sahip olduğunu göstermiştir. Metrik değişmezlik ise $\triangle$ CFI $<.01$ ve $\triangle$ RMSEA $<.015$ ölçütlerine dayalı olarak yapısal ve metrik model karşılaştırılarak test edilmiştir. Analizlerde elde edilen $\Delta \mathrm{CFI}=-.007$ ve $\Delta \mathrm{RMSEA}=.000$ değerleri, EIZZDÖ kısa formunun ergenliğin gelişim aşamalarına göre metrik değişmezliğe sahip olduğunu göstermiştir. Araştırmada, EİZDÖ kısa formunun cinsiyete (kız, erkek) göre ölçme değişmezliği de incelenmiştir. Cinsiyete dayalı çoklu grup doğrulayıcı faktör analizi sonuçları, yapısal ve metrik modelin veri setine mükemmel uyum sağladığını göstermiştir. Yapısal ve metrik modele ilişkin uyum iyiliği değerleri sırasıyla $\chi^{2}(24)=30.097, p>.01, \chi^{2} / s d=$ $1.672, \mathrm{CFI}=.980, \mathrm{RMSEA}=.033 \mathrm{CI}[.01, .05]$ ve $\chi^{2}(18)=34.778, p>.05, \chi^{2} / s d=1.449, \mathrm{CFI}=.982$, RMSEA $=.027$ CI $[.00, .05]$ olarak bulunmuştur. Yapısal modelin veri setine mükemmel uyumu, ölçme aracinın cinsiyete göre yapısal değişmezliğe sahip olduğunu göstermiştir. Ayrıca, yapısal model ile metrik model karşılaştırmasında tespit edilen $\triangle \mathrm{CFI}=.002$ ve $\triangle \mathrm{RMSEA}=-.006$ değerlerine göre EİZDÖ kısa formunun cinsiyete göre metrik değişmez olduğu belirlenmiştir.

\section{Sonuç ve Tartışma}

Bu araştırmada, McGeown ve diğerleri (2018) tarafından geliştirilen Ergenler İçin Zihinsel Dayanıklılık Ölçeği (EİZDÖ) Türkçe'ye uyarlanmış ve 11-18 yaş ortaokul ve lise örnekleminde psikometrik özellikleri incelenmiştir. İki ayrı örneklem grubundan elde edilen verilerin kullanıldığı çalışmada, öncelikle EİZDÖ’nin 18 maddeli altı boyutlu orijinal faktör yapısı test edilmiş, ölçüt-bağıntılı geçerlik ve güvenirlik düzeyi sınanmıştır. Ayrıca, McGeown ve diğerlerinden alınan uzman görüşü doğrultusunda mevcut çalışmada her bir boyutta o boyutu en iyi temsil eden (o boyutta en yüksek faktör yüküne sahip olan) birer madde seçilerek EİZDÖ’nin tek faktörlü altı maddeli kısa formu oluşturulmuştur. Birinci örneklem grubuna ilişkin veri analizi sonuçları, EIZZDÖ'nin orijinal uzun formu ile bu çalışmada oluşturulan kısa formunun faktör yapısının doğrulandığını göstermiştir. Ki-kare fark istatistiği ve model uyum indekslerinin (AIC, BIC ve ECVI) dikkate alındığı modeller arası karşılaştırmada, EİDÖ'nin kısa formunun uzun forma göre daha güçlü bir psikometrik yapıya sahip olduğu gözlenmiştir. Çalışmada, EİZDÖ uzun ve kısa formu ile Çocuk ve Genç Psikolojik Sağlamlık Ölçeği (ÇGPSÖ-12; Arslan, 2015; Liebenberg ve diğ., 2015) arasında saptanan anlamlı ilişkiler EİZDÖ’nin ölçüt-bağıntılı geçerliğe sahip olduğunu göstermiştir. EİZDÖ uzun ve kısa formda yer alan maddeler üzerinden hesaplanan Cronbach alfa katsayıları, hedef ölçme aracının her iki versiyonunun da güvenilir olduğunu göstermiştir. EİZDÖ’nin mevcut araştırmada oluşturulan kısa formunun psikometrik özelliklerinin sağlamlığını test etmek için ikinci bir örneklem 
grubundan veri toplanarak çapraz geçerlik ve güvenirlik çalışması yürütülmüsşür. İkinci örneklem grubuna ilişkin veri analizi sonuçları, EİZDÖ'nin tek faktörlü altı maddeli faktör yapısının doğrulandığını, kabul edilebilir iç tutarlık ve test-tekrar test güvenirlik düzeyine sahip olduğunu göstermiştir. Ayrıca, mevcut çalışmada, çoklu grup doğrulayıcı faktör analizi sonuçları, EIZZÖ'nin kısa formunun ergenliğin gelişim aşamalarına (ilk ergenlik, orta ergenlik ve ileri ergenlik) ve cinsiyete göre yapısal ve metrik değişmezliğe sahip olduğunu göstermiştir. Sonuç olarak, tüm bu bulgular, EİZDÖ'nin Türkçe uzun ve kısa formunun ortaokul ve liselerde ergenlerin zihinsel dayanıklılık düzeylerinin ölçümünde geçerli ve güvenilir bir ölçme aracı olarak kullanılabileceğini göstermiştir.

Mevcut çalışmada elde edilen bulguların, McGeown ve diğerlerinin (2018) EİZDÖ'ne ilişkin orijinal ölçek çalışmasında raporladıkları bulgularla tutarlık içerisinde olduğu görülmektedir. Orijinal çalışmada olduğu gibi (i) zorluklarla mücadele etme, (ii) kişilerarası yeteneklere güvenme, (iii) bireysel yeteneklere güvenme, (iv) duyguları kontrol etme, (v) yaşamı kontrol etme ve (vi) kendini adama boyutlarını içeren altı faktörlü ve 18 maddeli orijinal yapının hedef örneklemde doğrulandığı tespit edilmiştir. Orijinal çalışmadaki bulgularla tutarlı bir biçimde, mevcut çalışmada ölçek maddelerinin tümünün ait oldukları örtük yapıları anlamlı bir biçimde temsil ettikleri gözlenmiştir. Mevcut çalışmada, faktör yüklerinin .33 ve üzerinde olduğu belirlenmiştir. $\mathrm{Bu}$ bulgu, Nunnally’a (1978) göre kabul edilebilir faktör yüklerini temsil etmektedir. Ayrıca, doğrulayıcı faktör analizi sonucunda model uyumu değerlendirildiğinde $\chi^{2} / s d$, CFI, TLI ve RMSEA değerlerinin mükemmel düzeyde olduğu görülmüştür (Çokluk ve diğ., 2010). McGeown ve diğerlerinden (2018) alınan uzman görüşleri ve mevcut çalışmada elde edilen bulgular üzerinden oluşturulan EİZDÖ kısa formunun tek faktörlü altı maddeli yapısının da doğrulayıcı faktör analizinde mükemmel model uyumuna sahip olduğu tespit edilmiş̧ir (Çokluk ve diğ., 2010). Standardize edilmiş faktör yüklerinin tümünün anlamlı ve kabul edilebilir düzeyde olduğu belirlenmiştir (Nunnally, 1978). Ki-kare fark testi sonuçları ile AIC, BIC ve ECVI değerleri, EIZZDÖ’nin kısa formunun daha güçlü bir yapıya sahip olduğunu göstermiştir (Byrne, 2010). Orijinal çalışmada, EiZZDÖ ile akademik motivasyon ve iyi oluş arasında anlamlı ilişkiler saptanmıştır (McGeown ve diğ., 2018). Mevcut çalı̧̧ada, orijinal çalışmayla tutarlı bir biçimde EİZDÖ uzun ve kısa formundan elde edilen toplam puanlar ile ölçüt ölçme aracı (ÇGPSÖ-12; Arslan, 2015; Liebenberg ve diğ., 2015) arasında pozitif yönde orta düzeyde anlamlı korelasyonlar hesaplanmıştır. Başka bir deyişle, ampirik bulgular EIZZÖ'nin uzun ve kısa formunun hedef örneklemdeki ölçüt-bağıntılı geçerliğini desteklemiş̧ir. Orijinal çalışmada EİZDÖ'nin alt boyutlarına ilişkin Cronbach alfa katsayılarının .70 ve üzerinde olduğu rapor edilirken, mevcut çalışmada iç tutarlık katsayılarının .60 ile .88 arasında değiştiği tespit edilmiştir. Alanyazında genellikle iç tutarlık katsayısı için .70 ve üzeri değerler ölçüt alınmakla birlikte son yıllarda araştırmacıların .60 ve üzeri değerleri de kabul edilebilir sınırlar içerisine aldığı görülmektedir (Jain ve Angural, 2017). Bu bağlamda, mevcut çalışmada elde edilen bulguların EİZDÖ'nin güvenilir bir ölçme aracı olduğunu desteklediği söylenebilir. Bu çalışmada, EİZDÖ’nin uzun ve kısa formuna ilişkin iç tutarlık katsayıları sırasıyla .85 ve .72 olarak hesaplanmıştır. Bu bulguya göre, kısa formun güvenirlik düzeyinin göreceli olarak düşük olduğu görülmektedir. Alanyazında, kısa formu oluşturulan ölçeklerde madde sayısı uzun forma göre azaldığı için güvenirlik katsayılarında görülen azalmanın normal bir durum olduğuna işaret edilmektedir (Widaman, Little, Preacher ve Sawalani, 2011). Son olarak, bu çalışmada, çapraz geçerlik ve güvenirlik çalışması ile ölçme değişmezliği analizlerinden elde edilen bulguların da EIZZÖ’nin kısa formuna ilişkin psikometrik özellikleri desteklediği söylenebilir.

$\mathrm{Bu}$ araştırmada, EIZZDÖ'nden elde edilen toplam puanlar cinsiyet değişkeni açısından incelendiğinde, bağımsız gruplar için $t$-testi sonuçları, erkek öğrencilerin kız öğrencilere göre daha yüksek zihinsel dayanıklılık düzeyi rapor ettiklerini göstermiştir. Green ve Salkind'e (2005) göre, bu bulgunun etki büyüklüğü küçük olarak belirlenmiş̧tir. Mevcut çalışmada elde edilen bu bulgunun, orijinal çalışmada (McGeown ve diğ., 2018) elde edilen bulgularla tutarlık gösterdiği gözlenmiştir. Orijinal çalışmada, 11-18 yaş erkek öğrencilerin bireysel ve kişilerarası yeteneklere güven, kendini adama ve zorluklarla mücadele etme boyutlarında kız öğrencilere göre daha yüksek puan aldıkları rapor edilmiştir. Alanyazında benzer bir biçimde, çocuklar (St. Clair-Thompson ve diğ., 2017) ve yetişkinlerle (Crust ve diğ., 2014; St Clair-Thompson ve diğ., 2017) gerçekleştirilen zihinsel dayanıklılık araştırmalarında da erkekler lehine daha yüksek puanlar rapor edildiği gözlenmektedir. Mevcut çalışmada, EİZDÖ'nden elde edilen toplam puanlar okul düzeyi açısından karşılaştıııldığında, bağımsız gruplar için $t$-testi sonuçları, lise öğrencilerinin zihinsel dayanıklılık düzeylerinin ortaokul öğrencilerine göre daha düşük olduğunu göstermiş̧tir. Bu bulgunun, küçük bir etki büyüklüğüne sahip olduğu tespit edilmiştir (Green ve Salkind, 2005). Araştırmada elde edilen bulgunun, McGeown ve diğerlerinin (2018) orijinal çalışmada rapor ettikleri bulgudan farklılaştığı görülmüştür. Orijinal çalışmada, zihinsel dayanıklılık puanları ile yaş arasında anlamlı bir ilişski bulunmadığı tespit edilmiştir. Mevcut çalışmada farklılaşan bu bulguya ilişkin yorumlardan biri Türkiye'de yaş ve sınıf düzeyi arttıkça öğrencilerin daha çok akademik beklenti ve baskı hissetmeleri, bir üst öğrenim kurumuna geçiş sürecinde yüzbinlerce hatta bir milyonun üzerinde öğrenci sayısıyla beraber rekabet içeren merkezi sınavlara girmeleri olabilir.

$\mathrm{Bu}$ araştırmanın bazı sınılıılıkları da bulunmaktadır. Bu çalışmada elde edilen bulgular, Aydın ili Efeler ilçesinde merkez ortaokul ve liselerde öğrenim gören 11-18 yaş öğrencilerin verdikleri cevaplarla sınırlıdır. Başka bir 
ifadeyle, araştırmanın küçük bir ilin merkez ilçesinde gerçekleştirilmiş olması ve öğrencilerin çoğunlukla alt ve orta sosyo-ekonomik düzey ailelerden gelmelerinin araştırmanın genellenebilirliği açısından önemli bir sınırlılık olduğu söylenebilir. $\mathrm{Bu}$ araştırmada elde edilen bulguların genellenebilirliğini arttırmak için gelecek çalışmalarda farklı bölgelerden ve geniş örneklem gruplarından veri toplanıp ölçme aracının geçerlik ve güvenirliği test edilebilir. Ayrıca, çapraz geçerlik ve güvenirlik çalışması ile ölçme değişmezliğinin sadece kısa form üzerinde yürütülmesi, uzun form üzerinde bu çalışmaların gerçekleştirilmemesi bir sınırlılık olarak not edilebilir.

Mevcut araştırmanın belirtilen sınırlılıklara rağmen ulusal alanyazında önemli bir boşluğu doldurduğu ileri sürülebilir. $\mathrm{Bu}$ çalışmada Türkçe'ye uyarlaması gerçekleştirilen EİZDÖ’nin ulusal alanyazında eğitim ortamlarında zihinsel dayanıklılı̆̆ı inceleyen araştırmaların önünü açacağı söylenebilir. Mevcut çalışmada, EİZDÖ’nin 18 maddeli orijinal uzun formunun yanı sıra altı maddeli kısa formunun oluşturulmasının çok değişkenli ve boylamsal çalışmalar yürütecek araştırmacılar için daha kısa, ekonomik ve kullanışlı bir ölçme aracı seçeneği sunacağı söylenebilir. Zihinsel dayanıklılık pozitif psikoloji çalışmaları kapsamında ele alınacak kavramlardan biri olabilir. Gelecek çalışmalarda, ergenlerin zihinsel dayanıklılık düzeylerinin çeşitli değişkenler (örn., yaş, cinsiyet, sosyo-ekonomik düzey, aile yapısı vb.) açısından incelenmesi ve zihinsel dayanıklılı̆̆ etkileyen faktörlerin belirlenmesi okul psikolojik danışmanlarının önleme ve müdahale alanlarını daha çok aydınlatabilir. Zihinsel dayanıklılık, ortaokul ve lise öğrencilerinin aile, okul ve arkadaş ortamlarında karşılaş1labilecekleri muhtemel güçlüklerle başa çıkmalarında ve hedefleri doğrultusunda yaşamlarına devam etmelerinde önemli bir müdahale alanı olabilir. Günümüzde, ergenlerin yüz yüze doğal etkileşimler, ilişkiler ve yaşantılar yerine sanal ortamlarda daha çok zaman geçirmeye başlamaları nedeniyle başa çıkma mekanizmalarının sağlıklı gelişme olasılığı giderek zayıflamaktadır. Bu bağlamda, zihinsel dayanıklılık kavramının çocuk ve ergenlerle yürütülecek araştırmalarda incelenmesinin önemli olduğu düşünülmektedir.

Sonuç olarak, olumsuz ya da zorlayıcı durumlarla bireylerin başa çıkabilmelerinde ve hedeflerine odaklanıp başarılı olabilmelerinde zihinsel dayanıklılık önemli bir psikolojik yapıdır (Gucciardi ve diğ., 2015). Zihinsel dayanıklılık sadece bir başa çıkma becerisi olarak değil aynı zamanda pozitif psikoloji özellikleriyle yakından bağlantılı bir değişken olarak ele alınmaktadır (Connaughton ve diğ., 2008). Zorluklarla mücadele etme, kişilerarası ve bireysel yeteneklere güvenme, duyguları ve yaşamı kontrol etme ve kendini adama gibi özellikleri içeren çok boyutlu bir yapı olarak tanımlanan zihinsel dayanıklılık son yıllarda ruh sağlığı alanının yanı sıra eğitim ortamlarında da giderek artan bir şekilde çalışılmaya başlanmıştır (McGeown ve diğg., 2018). Okullarda yürütülen ilk çalışmalarda, zihinsel dayanıklılık düzeyinin gerek öğrencilerin bireysel psikolojik uyumları gerekse de okul sonuçları üzerinde önemli etkilere sahip olduğu tespit edilmiştir (örn., Crust ve diğ., 2014; McGeown ve diğ., 2018; St Clair-Thompson ve diğ., 2015; St Clair-Thompson ve diğ., 2017). Mevcut çalışmada, EİZDÖ'nin 11-18 yaş ergenlerde psikometrik özelliklerinin incelenmesi ve ulusal alanyazına geçerli ve güvenilir bir ölçme aracının kazandırılmasının ülkemiz eğitim alanyazınında yeni araştırmaların önünü açacağı söylenebilir. Gelecek çalışmalarda, zihinsel dayanıklılığın öncülleri ve sonuçları 11-18 yaş ergen örneklemlerinde incelenebilir. Araştırmalarda elde edilecek bulgular, zihinsel dayanıklılı̆̆ güçlendirmeye yönelik müdahale programlarının şekillendirilmesinde önemli rol oynayabilir. Günlük yaşam ve okul stres faktörleriyle (örn., kişisel/ailevi sorunlar, okul geçişleri, merkezi sınavlar vb.) başa çıkabilmede zihinsel dayanıklılık uygun bir müdahale alanı olabilir. 


\section{Kaynakça/References}

Arslan, G. (2015). Çocuk ve Genç Psikolojik Sağlamlık Ölçeği'nin (ÇGPSÖ-12) psikometrik özellikleri: Geçerlilik ve güvenirlik çalışması. Ege Eğitim Dergisi, 16(1), 1-12.

Byrne, B. M. (2010). Structural equation modeling with AMOS: Basic concepts, applications, and programming $\left(2^{\text {nd }}\right.$ ed.). New York: Routledge.

Chen, F. F. (2007). Sensitivity of goodness of fit indexes to lack of measurement invariance. Structural Equation Modeling: A Multidisciplinary Journal, 14(3), 464-504. doi: 10.1080/10705510701301834

Connaughton, D., Hanton, S., Jones, G., \& Wadey, R. (2008). Mental toughness research: Key issues in this area. International Journal of Sport Psychology, 39(3), 192-204.

Crust, L., Earle, K., Perry, J., Earle, F., Clough, A., \& Clough, P. J. (2014). Mental toughness in higher education: Relationships with achievement and progression in first-year university sports students. Personality and Individual Differences, 69, 87-91. doi:10.1016/j.paid.2014.05.016

Çokluk, Ö., Şekercioğlu, G. ve Büyüköztürk, Ş. (2010). Sosyal bilimler için çok değişkenli istatistik: SPSS ve LISREL uygulamaları. Ankara: Pegem Akademi.

Green, S. B., \& Salkind, N. J. (2005).Using SPSS for Windows and Macintosh: Analyzing and understanding data $\left(4^{\text {th }}\right.$ ed.). Upper Saddle River, NJ: Pearson Prentice Hall.

Gucciardi, D. F., Hanton, S., Gordon, S., Mallett, C. J., \& Temby, P. (2015). The concept of mental toughness: Tests of dimensionality, nomological network, and traitness. Journal of Personality, 83(1), 26-44. doi:10.1111/jopy.12079

Jain, S., \& Angural, V. (2017). Use of Cronbach's alpha in dental research. Medico Research Chronicles, 4(3), 285-291.

Jin, L., \& Wang, C. D. (2018). International students' attachment and psychological well-being: The mediation role of mental toughness. Counselling Psychology Quarterly, 31(1), 59-78. doi:10.1080/09515070.2016.1211510

Liebenberg, L., Ungar, M., \& LeBlanc, J. C. (2013). The CYRM-12: A brief measure of resilience. Canadian Journal of Public Health, 104(2), e131-e135. doi:10.1007/BF03405676

McGeown, S. P., St Clair-Thompson, H., \& Clough, P. (2016). The study of non-cognitive attributes in education: Proposing the mental toughness framework. Educational Review, 68(1), 96-113. doi:10.1080/00131911.2015.1008408

McGeown, S., St Clair-Thompson, H., \& Putwain, D. W. (2018).The development and validation of a Mental Toughness Scale for Adolescents. Journal of Psychoeducational Assessment, 36(2), 148-161. doi: $10.1177 / 0734282916673512$

Nunnally, J. C. (1978). Psychometric methods. New York, NY: McGraw-Hill.

Papageorgiou, K. A., Wong, B., \& Clough, P. J. (2017). Beyond good and evil: Exploring the mediating role of mental toughness on the Dark Triad of personality traits. Personality and Individual Differences, 119, 1923. doi:10.1016/j.paid.2017.06.031

Sağkal, A. S. (2019). Direct and indirect effects of strength-based parenting on adolescents' school outcomes: Exploring the role of mental toughness. Manuscript submitted for publication.

Sağkal, A. S., \& Özdemir, Y. (2019). Strength-based parenting and adolescents' psychological outcomes: The role of mental toughness. Journal of Psychologists and Counsellors in Schools. Advanced online publication. doi:10.1017/jgc.2019.2.

Santrock, J. W. (2012). Ergenlik (Çev. Ed. Siyez, D. M. ). Ankara: Nobel. (Özgün Çalışma, 2012) 
Sorensen, S., Schofield, G., \& Jarden, A. (2016). A systems-approach model of mental toughness: Understanding inputs, processes and outputs. Psychology, 7(12), 1402-1423. doi:10.4236/psych.2016.712141

St Clair-Thompson, H., Bugler, M., Robinson, J., Clough, P., McGeown, S. P., \& Perry, J. (2015). Mental toughness in education: Exploring relationships with attainment, attendance, behaviour and peer relationships. Educational Psychology, 35(7), 886-907. doi:10.1080/01443410.2014.895294

St Clair-Thompson, H., Giles, R., McGeown, S. P., Putwain, D., Clough, P., \& Perry, J. (2017). Mental toughness and transitions to high school and to undergraduate study. Educational Psychology, 37(7), 792809. doi:10.1080/01443410.2016.1184746

Tabachnick, B. G., \& Fidell, L. S. (2007). Using multivariate statistics $\left(5^{\text {th }}\right.$ ed.). Boston, MA: Pearson Education, Inc.

Widaman, K. F., Little, T. D., Preacher, K. J., \& Sawalani, G. M. (2011). On creating and using short form scales in secondary research. In K. H. Trzesniewski, M. Donnellan, \& R. E. Lucas (Eds.), Secondary data analysis: An introduction for psychologists (pp. 39-61). Washington, DC: American Psychological Association. 